\title{
COMMENT ON HOUSTON'S ARGUMENTS
}

\author{
Craig M. Allen
}

\author{
UNIVERSITY OF TEXAS AT DALLAS
}

Houston's arguments focus on two main issues: the noninclusion of a bias term in the generalization and the disputed usefulness of the relationship in a pair-wise concurrent choice setting. A third, minor issue is raised by Houston regarding the "restrictiveness" of the relationship

$$
\frac{B_{i}}{B_{j}}=f\left(\frac{R_{i}}{R_{j}}\right) .
$$

These arguments will be addressed in what I consider to be an increasing order of importance.

Houston suggests that the above relationship between behavior and reinforcement ratios (which is the least restrictive of any possible relationship) is in some way more restrictive than a similar relationship he proposes between behavior and reinforcement proportions. Although I agree that his is a different relationship, I see no cause for its being called less restrictive. It may be a productive relationship to study further, but I see no intrinsic superiority of one starting point over the other (except as the one equation leads to an interesting insight into the generalized matching law).

The argument Houston raises that the proof is "incompatible with any value of $b$ [the bias term] other than one" errs only by being myopic. By any number of reasonable assumptions the notion of value (see Rachlin, 1971) can be substituted for reinforcement rate in each equation. Hence

$$
\frac{B_{i}}{B_{j}}=f\left(\frac{V_{i}}{V_{j}}\right)=f\left(\frac{b_{i}}{b_{j}} \cdot \frac{R_{i}}{R_{j}}\right),
$$

where $V$ is the "value," and $b$ is the multiplicative bias term associated with an alternative

Reprints may be obtained from Craig M. Allen, University of Texas at Dallas, Callier Center, 1966 Inwood Road, Dallas, Texas 75235. (cf. de Villiers, 1977; Killeen, 1972; Miller, 1976). The generalization proceeds exactly as before, showing that

$$
\frac{B_{i}}{B_{j}}=\left(\frac{b_{i}}{b_{j}} \cdot \frac{R_{i}}{R_{j}}\right)^{s}=\frac{b_{i}^{\prime}}{b_{j}^{\prime}}\left(\frac{R_{i}}{R_{j}}\right)^{s},
$$

which does indeed include a bias term. The bias argument is not critical to the appearance of the exponent term and was not discussed in Allen (1981) for this reason. Virtually any parameter can be added ad hoc, so the generalization in question does not exclude any type of asymmetry.

Houston's final argument against the applicability of the functional equation in pairwise concurrent choice settings raises the purely theoretical question, "Are there sources of unscheduled reinforcement?" If there are not, then, as Houston suggests, Equation 9 holds. Houston correctly points out that this equation does not lead to the same conclusions as Equation 4. However, if, as several authors have supposed (e.g., de Villiers, 1977; Herrnstein, 1970, 1974), there exists a source of unscheduled reinforcement, $R_{o}$, then the generalization stands. Consider, for example, two distinct pair-wise choice settings offering, respectively, alternative pairs $(i, j)$ and $(k, l)$. Plugging directly into Equation 5, two parallel sets of equations (for the two situations) can be developed as follows:

$$
\begin{aligned}
& f\left(\frac{R_{i}}{R_{j}}\right)=f^{\prime}\left(\frac{R_{i}}{R_{o}}\right) \cdot f\left(\frac{R_{o}}{R_{j}}\right) ; \\
& f^{\prime}\left(\frac{R_{k}}{R_{l}}\right)=f^{\prime}\left(\frac{R_{k}}{R_{o}}\right) \cdot f^{\prime}\left(\frac{R_{o}}{R_{l}}\right),
\end{aligned}
$$

from which proceeds

$$
\begin{aligned}
f(c \cdot d) & =f(c) \cdot f(d) ; \\
f^{\prime}(p \cdot q) & =f^{\prime}(p) \cdot f^{\prime}(q),
\end{aligned}
$$

where $c, d, p, q$ are all positive constants (cf. 
Equation 6 in Houston's article). The logical result is still

$$
f(x)=x^{8} ; \quad f^{\prime}(x)=x^{8 \prime} ;
$$

but, by the assumption that all reinforcement ratios are transformed by the same function $f$,

$$
f(x)=f^{\prime}(x)=x^{8} \text {. }
$$

That is, by acknowledging the existence of sources of unscheduled reinforcement, $R_{o}$, the generalization holds even across separate pairwise choice settings.

The power form of the matching law is already known to fit data, but the reason it does so is not known. The proof in question provides a formal basis, based on specific assumptions, for believing that the power function equation is not just an aid to help account for noisy data. Rather, the proof suggests that the power function form is a result of specific, testable assumptions being true. The questions that might better be asked are: Does animal behavior reflect ratio-type comparisons? Does animal behavior reflect consistent operations on (i.e., deviations from) reinforcement ratios? And, as Houston's probing has asked: In "two" alternative choice situations, is it reasonable to consider sources of unscheduled reinforcement as a third alternative? To the extent that these answerable questions are answered in the affirmative, then the appearance of the exponent in the matching equation is explained. For a real case against the proof, these questions, I believe, are the questions that should be addressed.

\section{REFERENCES}

Allen, C. M. On the exponent in the "generalized" matching equation. Journal of the Experimental Analysis of Behavior, 1981, 35, 125-127.

de Villiers, P. A. Choice in concurrent schedules and a quantitative formulation of the law of effect. In W. K. Honig \& J. E. R. Staddon (Eds.), Handbook of operant behavior. Englewood Cliffs, N.J.: Prentice-Hall, 1977.

Herrnstein, R. J. On the law of effect. Journal of the Experimental Analysis of Behavior, 1970, 13, 243266.

Herrnstein, R. J. Formal properties of the matching law. Journal of the Experimental Analysis of $\mathrm{Be}$ havior, 1974, 21, 159-164.

Killeen, P. The matching law. Journal of the Experimental Analysis of Behavior, 1972, 17, 489-495.

Miller, H. L., Jr. Matching-based hedonic scaling in the pigeon. Journal of the Experimental Analysis of Behavior, 1976, 26, 335-347.

Rachlin, H. On the tautology of the matching law. Journal of the Experimental Analysis of Behavior, $1971,15,249-251$.

Received January 18, 1982

Final acceptance March 15, 1982 